\title{
Fusarium Antifungal Activities of Copper Nanoparticles Synthesized by a Chemical Reduction Method
}

\author{
Pham Van Viet, ${ }^{1,2}$ Hai Thi Nguyen, ${ }^{2}$ Thi Minh Cao, ${ }^{2}$ and Le Van Hieu ${ }^{1}$ \\ ${ }^{1}$ Faculty of Materials Science, University of Science, Vietnam National University Ho Chi Minh City, 227 Nguyen Van Cu Street, \\ District 5, Ho Chi Minh City 700000, Vietnam \\ ${ }^{2}$ CM Thi Laboratory, Ho Chi Minh City University of Technology (HUTECH), 475A Dien Bien Phu Street, Binh Thanh District, \\ Ho Chi Minh City 700000, Vietnam \\ Correspondence should be addressed to Pham Van Viet; pvviet@hcmus.edu.vn and Le Van Hieu; lvhieu@hcmus.edu.vn
}

Received 21 March 2016; Revised 20 June 2016; Accepted 29 June 2016

Academic Editor: Lavinia Balan

Copyright (C) 2016 Pham Van Viet et al. This is an open access article distributed under the Creative Commons Attribution License, which permits unrestricted use, distribution, and reproduction in any medium, provided the original work is properly cited.

We report on the process of synthesizing copper nanoparticles ( $\mathrm{Cu} N p s)$ for a short reactive time by chemical reduction method with a support of CTAB reductive agent. Their properties were determined by ultraviolet-visible (UV-Vis) absorption spectrum, the X-ray (XRD) analysis, Fourier transform infrared spectroscopy (FT-IR), and Transmission Electron Microscopy (TEM) images. The antifungal activity of $\mathrm{Cu}$ Nps was evaluated by testing against Fusarium sp. The Cu Nps were obtained with the average size in the range of 20-50 nm having spherical shape. The survey shows that when $\mathrm{Cu}$ Nps were used at $450 \mathrm{ppm}$ concentration in 9-day incubation, $93.98 \%$ of fungal growth was inhibited.

\section{Introduction}

Transition metals and their oxides are widely used in materials because of their specific electrical, structural, catalytic, optical, and magnetic properties [1-3]. Among transition metal materials, copper is the most important material. The unique catalytic and optical properties show that copper nanoparticles ( $\mathrm{Cu} \mathrm{Nps}$ ) are potential candidates for the reaction of $\mathrm{H}_{2} \mathrm{O}$ dissociation [4], used in ultrafast catalytic activity for the degradation of some organic dyes such as methylene blue (MB) and rose bengal (RB) [5], and applied in a wide variety of conductive inks for printing in electronics [6-8] as well as antifungal/antibacterial applications [9-15]. In particular, the fungus inhibition efficiency of $\mathrm{Cu} \mathrm{Nps}$ is better than other metal nanoparticles, such as $\mathrm{Al}, \mathrm{Fe}, \mathrm{Mn}, \mathrm{Ni}$, $\mathrm{Zn}$, and products of bigger size $\mathrm{Cu}$ particles [16].

Fusarium species (sp.) is the largest expansion in "Tuberculariaceae" family and it exists in host plants and is the major cause which wilts host plants [17]. Because the colonies spread across the tissue and fill xylem vessels, water transport process is hindered, making the plants wilt $[16,18,19]$. Furthermore, Fusarium sp. also produces a number of toxic substances in the host vascular tree which can also cause wilting [20]. Fusarium sp. is a common fungal disease on many crops and it is one of the most devastating diseases spotted on tomato, potato, dragon fruit, watermelon plants and other cucurbits, and so forth [18, 21, 22].

Currently, the antagonistic organisms, such as Bacillus coagulans [23] or a wide variety of chemicals to eliminate harmful microorganisms are often used. In particular, the use of generic drugs with a large amount of copper leads to copper residues in produce as well as higher soil and water pollution. Plant microelements as $\mathrm{Cu}$ Nps are known to play critical roles in plant disease resistance through enzyme activation for defense barrier production [16]. Furthermore, the use of $\mathrm{Cu}$ Nps helps to reduce the amount of chemicals in the prevention against Fusarium sp. fungal diseases. According to Durán et al. [24] and Prabhu et al. [25], like silver nanoparticles, $\mathrm{Cu}$ Nps also demonstrated the sizedependent antibacterial activity. Therefore, to achieve the maximum antibacterial activity, it is necessary to develop various methods for the synthesis of monodisperse copper nanoparticles with small size; that is, the ratio of surface area to volume is large $[26,27]$. 
There are many methods for synthesis of $\mathrm{Cu}$ Nps such as hydrothermal [28], photoreduction [29-31], thermal decomposition [11], and polyol and microwave-assisted polyol method [9, 32, 33]. However, the production of $\mathrm{Cu} \mathrm{Nps}$ is much more challenging in comparison to noble metals because $\mathrm{Cu}$ Nps are placed in the open air leading to the aggregation immediately due to surface oxidation. To avoid this problem, an inert environment, such as argon or nitrogen, inorganic solvents, protective polymers, or surfactants, was used [34]. In the chemical reduction techniques, a copper salt is reduced by a reducing agent such as sodium borohydride $\left(\mathrm{NaBH}_{4}\right)$, hydrazine $\left(\mathrm{N}_{2} \mathrm{H}_{4}\right)$, ascorbate, polyol, isopropyl alcohol with cetyltrimethylammonium bromide (CTAB), and glucose [34]. Besides, a literature review of Xiong et al. has reported that a simple, environmentally friendly, and cost-effective method for preparing highly stable dispersions of $\mathrm{Cu}$ Nps was used from green chemicals, such as Vitamin C (ascorbic acid, AsA) [35]. However, the ascorbic acid is a weak reducing agent; the reaction rate in the water solvent is slow; therefore, it takes more time to form $\mathrm{Cu}$ Nps (approximately 14 hours) [36-38]. In addition, the higher reaction temperature or longer reaction time favors the growth rate of pure metallic $\mathrm{Cu}[39,40]$. Therefore, reductive chemicals such as ascorbic acid and CTAB were combined in aqueous solution at $80^{\circ} \mathrm{C}$ to improve reaction rate in this study. Moreover, we study the surface plasmon resonance effect of $\mathrm{Cu}$ Nps via UV-Vis spectrum and investigation of the Fusarium sp. antifungal properties at various $\mathrm{Cu} \mathrm{Nps}$ concentrations. The purpose of this investigation shows that $\mathrm{Cu}$ Nps are a significant potential as bactericidal agents.

\section{Experimental}

2.1. Materials. Cu Nps solutions were prepared by chemical reduction method from chemicals and materials including copper (II) chloride dehydrate $\left(\mathrm{CuCl}_{2} \cdot 2 \mathrm{H}_{2} \mathrm{O}\right.$, Merck, Germany, 99.99\%), cetyltrimethylammonium bromide $\left[\left(\mathrm{C}_{16} \mathrm{H}_{33}\right) \mathrm{N}\left(\mathrm{CH}_{3}\right)_{3} \mathrm{Br}\right.$, CTAB, India, 99.99\%], deionized (DI) water from Thermo Scientific Equipment, ascorbic acid $\left(\mathrm{C}_{6} \mathrm{H}_{8} \mathrm{O}_{6}\right.$, India, 99.99\%), D-glucose $\left(\mathrm{C}_{6} \mathrm{H}_{12} \mathrm{O}_{6}\right.$, Sigma-Aldrich, 99.5\%), chloramphenicol $\left(\mathrm{C}_{11} \mathrm{H}_{12} \mathrm{Cl}_{2} \mathrm{~N}_{2} \mathrm{O}_{5}\right)$, double-distilled water (Vietnam), and the TCBS agar (Difco, USA). The potatoes and dragons were made in Vietnam.

2.2. Synthesis of Cu Nps by a Chemical Reduction Method. In a typical synthesis, 0.1712 gram $\mathrm{CuCl}_{2} \cdot 2 \mathrm{H}_{2} \mathrm{O}$ was stirred with $50 \mathrm{~mL}$ DI water in 15 minutes to form $\mathrm{CuCl}_{2}$ solution having blue color. Next, $10 \mathrm{~mL}$ ascorbic acid $(0.1 \mathrm{M})$ was slowly dropped into the above solution and the mixture solution achieved a $\mathrm{pH}$ of around 5. To survey the effect of CTAB, $10 \mathrm{~mL}$ CTAB $(0.025 \mathrm{M})$ solution was slowly dropped into the mixture of $\mathrm{CuCl}_{2}$ solution and ascorbic acid. These mixtures were kept at $80^{\circ} \mathrm{C}$ until a red-brown solution was obtained. During the course of the reaction, the solution turned into red-brown color indicating the formation of $\mathrm{Cu}$ NPs.

2.3. Characterization of $\mathrm{Cu}$ Nps. To examine the existence of $\mathrm{Cu} \mathrm{Nps}$ in the synthesized solution, we determined the surface plasmon resonance properties throughout the absorption spectra in the UV-Vis band taken by using UV-visible spectrophotometer (U2910, Hitachi, Japan). The Fourier transform infrared spectroscopy (FT-IR) spectrum was recorded on a FT-IR spectrometer (Vertex 80, Bruker, Germany) with the range of 400 to $4000 \mathrm{~cm}^{-1}$ in transmission mode at room temperature to identify the functional group present on the samples and responsible for the stability of nanoparticles. Morphologies include the sizes and shapes of the samples which were recorded by Transmission Electronic Microscope (TEM) on a JEM 1400 instrument. The Xray diffraction (XRD) analysis was carried out (Bruker D8 Advance 5005) at a voltage of $45 \mathrm{kV}$ with $\mathrm{Cu} \mathrm{K} \alpha$ radiation $(\lambda$ $=1.5406 \AA$ ) to examine the crystalline phase of synthesized nanoparticles.

2.4. The Test of the Fusarium sp. Antifungal Activity of $\mathrm{Cu}$ Nps. Firstly, Fusarium sp. fungal samples were taken from tomato and dragon fruit plants. After that, Fusarium sp. fungal samples were isolated in agar water media. This media was chosen for the fungal isolation media including $1000 \mathrm{~mL}$ distilled water, $20 \mathrm{~g} / \mathrm{L}$ agar, and $0.25 \mathrm{~g} / \mathrm{L}$ chloramphenicol. Secondly, the fungal samples were isolated and incubated in potato D-glucose agar (PDA) media including $1000 \mathrm{~mL}$ of distilled water, $20 \mathrm{~g} / \mathrm{L}$ agar, $200 \mathrm{~g}$ potatoes, $20 \mathrm{~g}$ D-glucose, and $0.25 \mathrm{~g} / \mathrm{L}$ chloramphenicol. Thirdly, we recorded the temperature, date, and time of incubated samples at survey times and observed the growth of fungus. Finally, we measured diameter of fungal colonies and estimated the inhibition efficiency of $\mathrm{Cu} \mathrm{Nps}$ at various concentrations. The inhibition percentage of fungal plant pathogens was calculated by using formula as suggested by Vincent [41]:

$$
\text { Inhibition Efficency }(I, \%)=\frac{C-T}{C} \times 100 \text {. }
$$

Hence, $I$ is inhibition percentage; $C$ is growth of fungal plant pathogens in control (mm), and $T$ is growth of fungal plant pathogens in dual culture plate $(\mathrm{mm})$.

\section{Results and Discussion}

3.1. Preparation of Cu Nps. Figure 1(a) shows the absorption spectra of the prepared samples and these samples after being stirred for 15 minutes. The absorption spectrum of the prepared samples shows two peaks at $420 \mathrm{~nm}$ and $560 \mathrm{~nm}$ wavelengths. Nevertheless, the absorption spectrum of the samples which were stirred for 15 minutes shows only a peak at $560 \mathrm{~nm}$ wavelength and its intensity has significantly increased. The peak at $560 \mathrm{~nm}$ relates to existence of the $\mathrm{Cu}$ Nps [31] and peaks from $400 \mathrm{~nm}$ to $420 \mathrm{~nm}$ of wavelength relate to the copper oxide nanoparticles [32]. According to [42-45], the peak at 550-600 $\mathrm{nm}$ of the wavelength can be assigned to the absorption of $\mathrm{Cu} \mathrm{Nps}$. This result indicated the rapid formation of the $\mathrm{Cu} \mathrm{Nps}$ for 15-minute reaction. However, if the synthesized sample with a reductive chemical as ascorbic acid is used, $\mathrm{Cu}$ Nps will be not formed for 2-hour reaction but for 14 -hour reaction. The statement mentioned above was demonstrated by the absorption spectrum of the synthesized sample at only ascorbic acid condition for 2-hour 


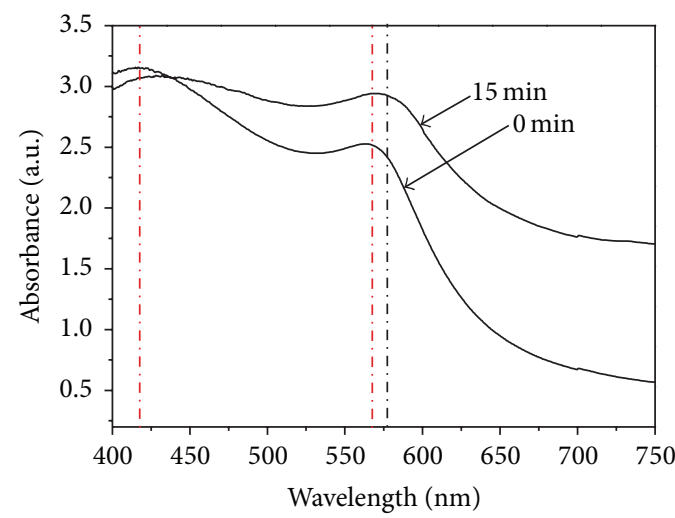

(a)

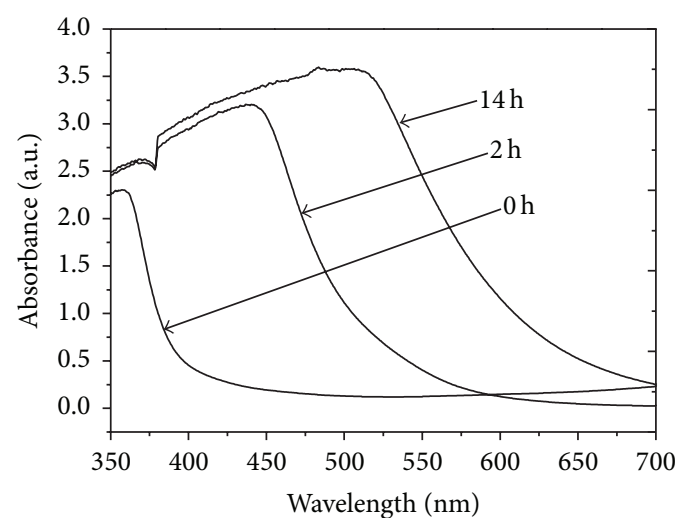

(b)

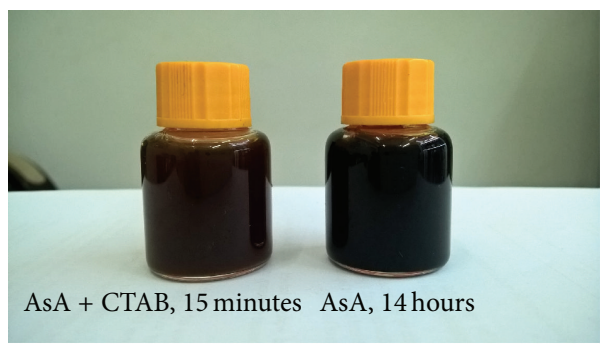

(c)

FIGURE 1: Absorption spectra of the samples (a) supported CTAB and (b) nonsupported CTAB at different reaction periods and (c) the color of the synthesized samples.

and 14-hour reactions (Figure 1(b)). This result agrees with Xiong et al.' research [35].

Figure 1(c) shows the color of the synthesized sample with ascorbic acid and CTAB reduction chemicals for a 15-minute period and the other one synthesized only with ascorbic acid for 14-hour period of time. This result exhibited that the synthesized sample with only ascorbic acid was brown while the synthesized sample with the support of CTAB was redbrown.

Furthermore, the $\mathrm{Cu}$ Nps solution synthesized by the support of $\mathrm{CTAB}$ was evaporated at $150^{\circ} \mathrm{C}$ for 2 hours at atmosphere. After that, the $\mathrm{Cu}$ Nps powder was characterized by XRD pattern. Figure 2 exhibits the XRD pattern of $\mathrm{Cu}$ Nps powder. The peaks observed at $2 \theta$ values of $43.39^{\circ}$, $50.49^{\circ}$, and $74.18^{\circ}$ correspond to (111), (200), and (220) planes of metallic $\mathrm{Cu}[11,30,46]$. Apart from the metallic $\mathrm{Cu}$ peaks, several other diffraction peaks appeared at $36.54^{\circ}$ and $61.6^{\circ}$ representing the formation of cubic copper (I) oxide nanocrystals $[37,47,48]$. The result was explained that $\mathrm{Cu}$ Nps might be formed by oxidation when the solution was evaporated at $150^{\circ} \mathrm{C}$ for 2 hours at atmosphere.

3.1.1. Fourier Transform Infrared Spectroscopy (FTIR) Analysis. Figure 3 represents the appearance of some different peaks, such as peaks at $3400 \mathrm{~cm}^{-1}, 1630-1761 \mathrm{~cm}^{-1}, 1142-1345 \mathrm{~cm}^{-1}$, and $724-928 \mathrm{~cm}^{-1}$ bands of the wavenumber. According to Xiong et al. [35], the peaks were observed at $3481 \mathrm{~cm}^{-1}$, $1718 \mathrm{~cm}^{-1}$, and $1681 \mathrm{~cm}^{-1}$ corresponding to the $-\mathrm{OH}$ stretch of the $\mathrm{H}_{2} \mathrm{O}$ molecules, oxidized ester carbonyl groups, and conjugated carbonyl groups, respectively. Besides, according

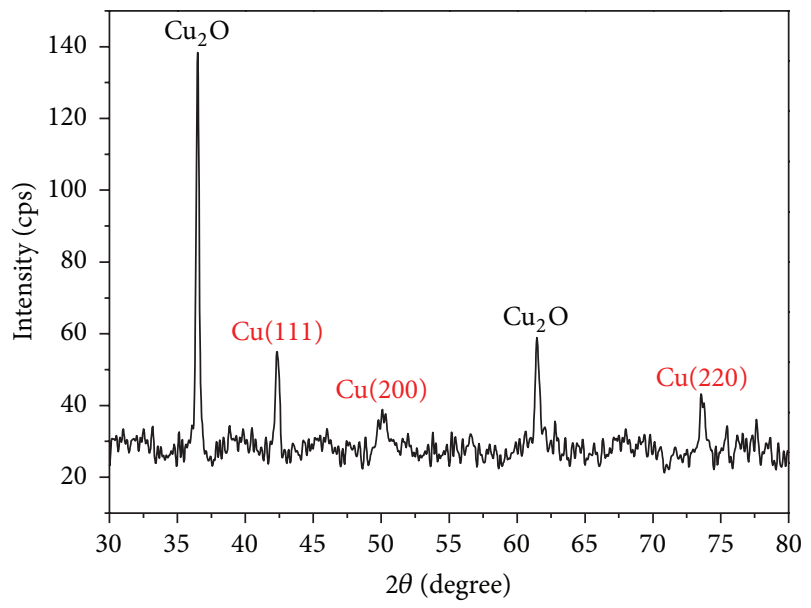

FIGURE 2: XRD pattern of the Cu Nps powder.

to Viana et al., peaks at broadband of the $900-1000 \mathrm{~cm}^{-1}$ were presented for $\mathrm{N}-\mathrm{CH}_{3}$ stretching vibration [49]. The appearance of these peaks was caused by the residual CTAB after reactions creating $\mathrm{Cu} \mathrm{Nps}$ completely.

3.1.2. Transmission Electron Microscopy (TEM) Analysis. The sizes and shapes of $\mathrm{Cu}$ Nps were characterized by TEM images. Figure 4 shows that the shapes of $\mathrm{Cu}$ NPs are spherical with uniform sizes. The particles size of $\mathrm{Cu} \mathrm{Nps}$ is in the range from $20 \mathrm{~nm}$ to $50 \mathrm{~nm}$. Besides, the shapes of $\mathrm{Cu} \mathrm{Nps}$ are mainly spherical, which relates to copper phase [50]. 


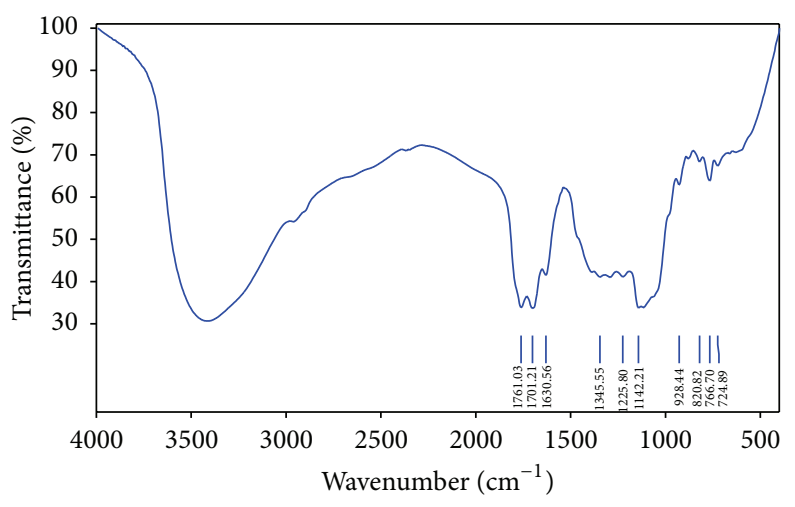

Figure 3: FTIR spectrum of the $\mathrm{Cu}$ Nps solution.

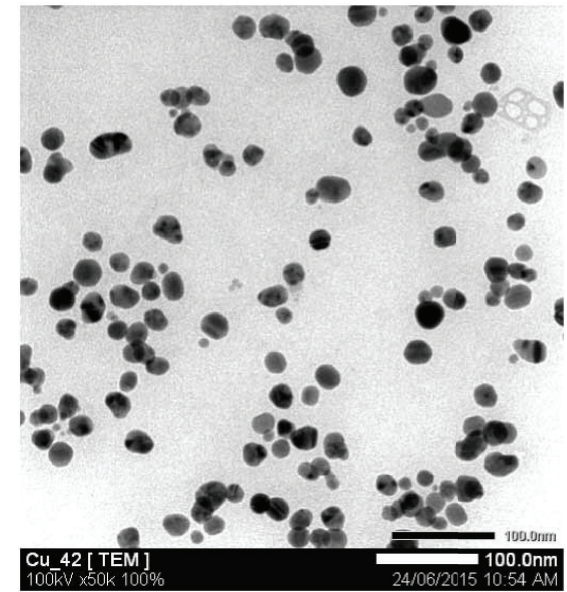

(a)

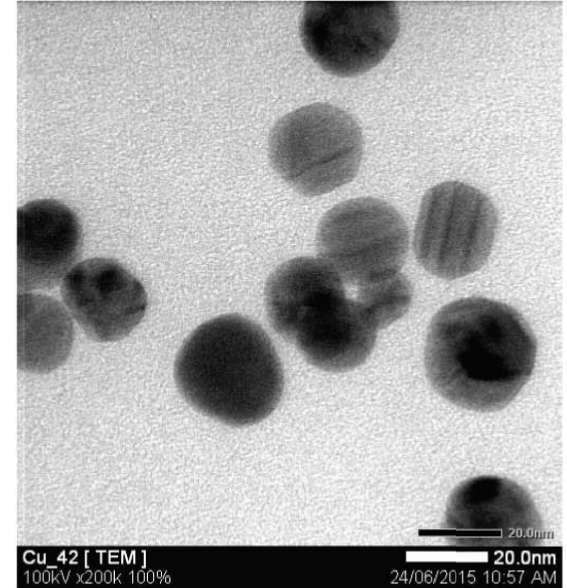

(b)

Figure 4: TEM images of $\mathrm{Cu}$ Nps solution for different scales: (a) $100 \mathrm{~nm}$ and (b) $20 \mathrm{~nm}$.

3.2. The Fusarium sp. Antifungal Properties of Cu Nps Solutions. We survey the effect of $\mathrm{Cu} \mathrm{Nps}$ solutions on the development of Fusarium sp. by determining the diameter of the fungal colonies on the samples including the non$\mathrm{Cu}$ Nps solution sample and other samples with $\mathrm{Cu} \mathrm{Nps}$ solution with the concentrations of $300 \mathrm{ppm}, 380 \mathrm{ppm}$, and $450 \mathrm{ppm}$, respectively. The diameter of the fungal colonies was determined after the incubation periods of 3 days, 6 days, and 9 days, respectively. The images of colonies according to incubation period at various $\mathrm{Cu}$ Nps concentrations are exhibited in Figure 5. These results show that $\mathrm{Cu} \mathrm{Nps}$ inhibited the development of Fusarium sp. It demonstrated that the diameter of colonies in all samples was supplemented with $\mathrm{Cu}$ Nps being smaller than the reference sample. In 3-day incubation, the diameters of fungal colonies for additional formulations of $300 \mathrm{ppm}$ and $380 \mathrm{ppm}$ of $\mathrm{Cu} \mathrm{Nps}$ were measured about $8.67 \mathrm{~mm}$, while the reference sample developed rapidly with the diameter of the fungal colony being about $15.33 \mathrm{~mm}$. The fungal colony of the sample at the $\mathrm{Cu}$ Nps concentration of $300 \mathrm{ppm}$ is still developing in 9-day incubation, while the diameter of the fungal colony of the samples at the $\mathrm{Cu} \mathrm{Nps}$ concentration of $380 \mathrm{ppm}$ was approximately $44 \mathrm{~mm}$ after they were incubated for 6 days and it almost unchanged the next 3 days. Meanwhile, the diameter of Fusarium sp. colony was $5 \mathrm{~mm}$. It remains after being incubated for 9 days. In addition, Figure 6 shows the change of the diameter of fungal colonies at various incubation periods for various concentrations of $\mathrm{Cu} \mathrm{Nps}$ solutions. These diagrams show that the more the $\mathrm{Cu} \mathrm{Nps}$ concentration increases, the more the diameter of fungal colonies decreases. Remarkably, the diagram of the diameter of the colonies with the $\mathrm{Cu}$ Nps concentration of $450 \mathrm{ppm}$ was a straight line. This result demonstrated that the diameter of the fungal colony almost does not increase in the samples at the $\mathrm{Cu}$ Nps concentration of $450 \mathrm{ppm}$.

From these above results, we determined the Fusarium sp. inhibition efficiency of $\mathrm{Cu} \mathrm{Nps}$ solution and it was represented in Figure 7. These results show that the inhibition efficiency of $\mathrm{Cu} \mathrm{Nps}$ was good in the in vitro condition. However, the inhibition efficiency of $\mathrm{Cu}$ Nps increases according to the concentration used. In a 3-day incubation, $\mathrm{Cu} \mathrm{Nps}$ solutions inhibited $43 \%$ of growth of fungi of the samples at the concentration of $300 \mathrm{ppm}$ and $380 \mathrm{ppm}$. Meanwhile, $\mathrm{Cu}$ Nps solution could inhibit $67.38 \%$ of the fungal growth at $450 \mathrm{ppm}$ concentration after being incubated for 3 days and reaches $93.98 \%$ if incubated for 9 days. At this time the 

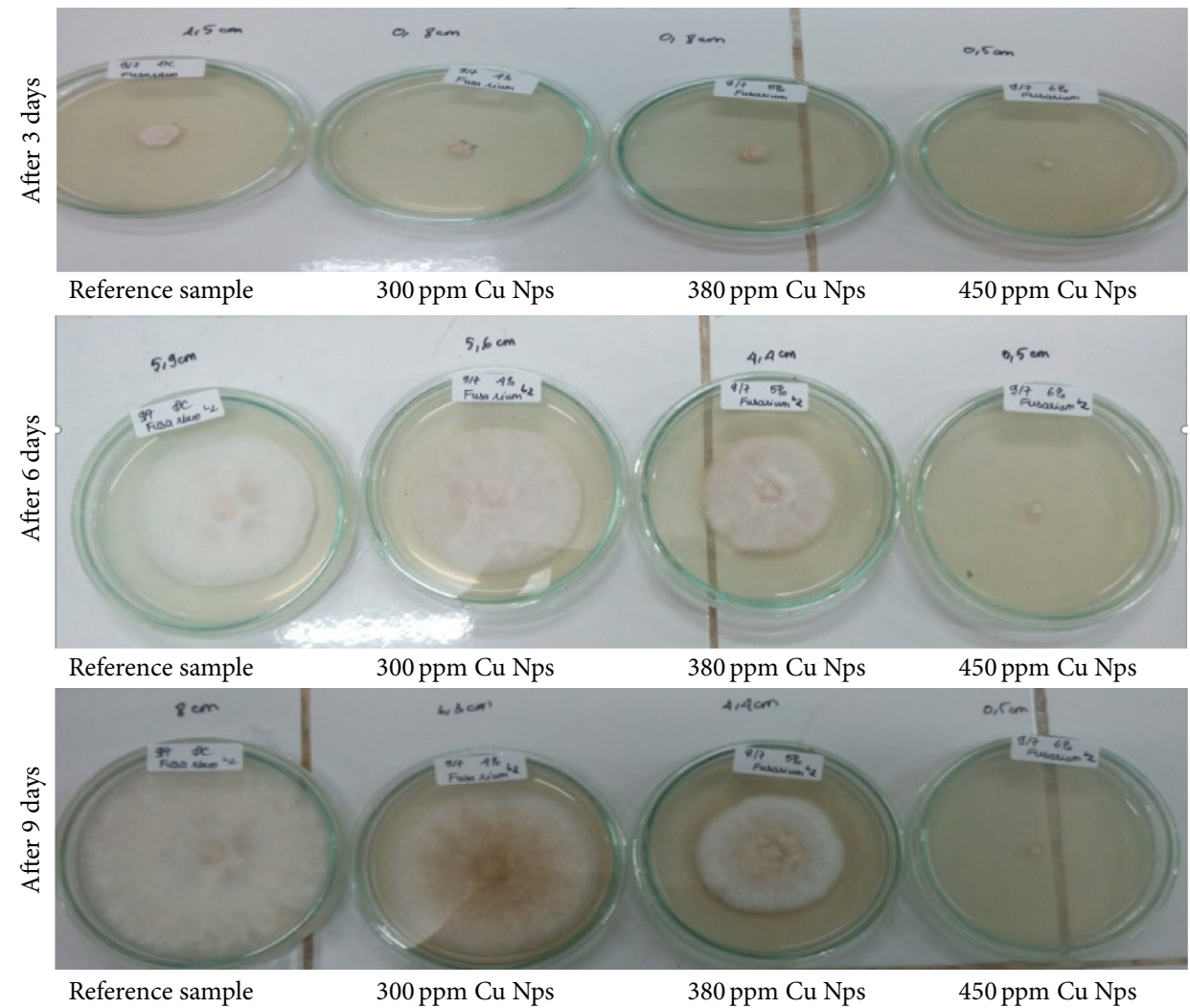

FIgURE 5: The diameter of Fusarium sp. colonies according to incubation period at various Cu Nps solution concentrations.

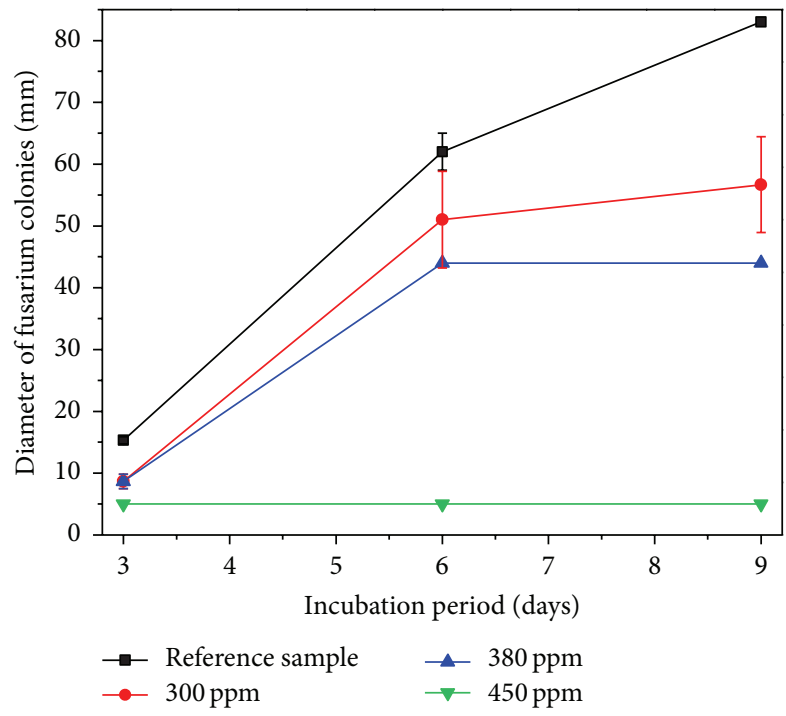

FIgURE 6: The diagram of the formation of the diameter of Fusarium sp. colonies according to incubation period at various $\mathrm{Cu} \mathrm{Nps}$ solution concentrations.

results show that inhibition efficiency of $\mathrm{Cu}$ Nps solution went up significantly due to $450 \mathrm{ppm}$ concentration dish; the fungi were inhibited intensively and no longer grew in a 3-day incubation. In contrast, the fungi in the reference sample still grew normally and their diameter increased constantly.

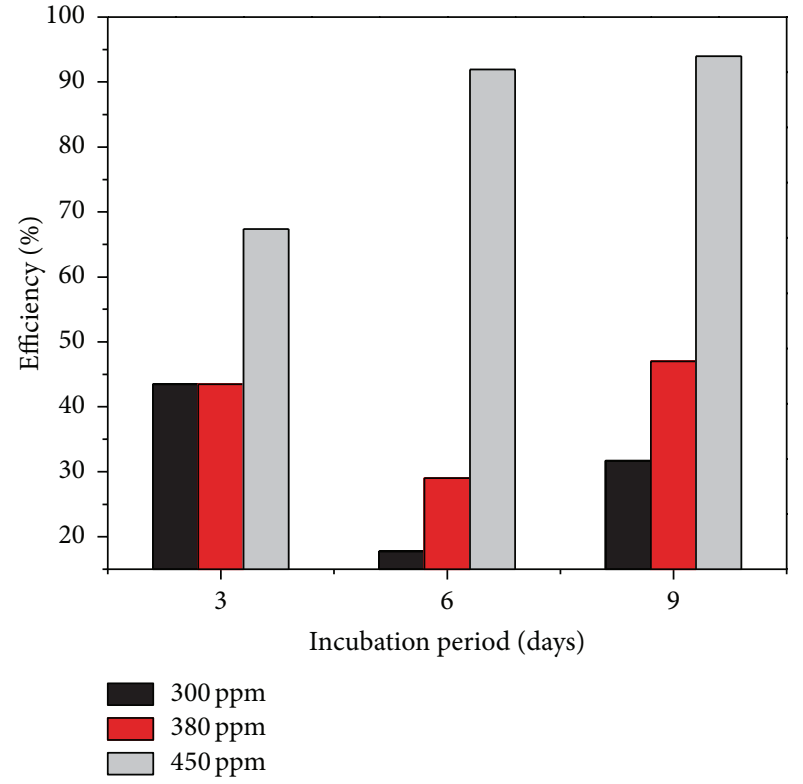

Figure 7: The Fusarium sp. inhibition efficiency of Cu Nps solutions.

\section{Conclusion}

We successfully prepared $\mathrm{Cu}$ Nps for a short reaction time (about 15-minute reaction) by chemical reduction method with a support of CTAB reductive agent. The absorption 
spectrum of $\mathrm{Cu}$ Nps solutions prepared after a 15-minute reaction shows an absorption peak at $560 \mathrm{~nm}$ wavelength, a typical peak for the existence of $\mathrm{Cu}$ Nps. The size of $\mathrm{Cu}$ Nps is in the range from $20 \mathrm{~nm}$ to $50 \mathrm{~nm}$ and their shapes are mainly spherical. The more the $\mathrm{Cu}$ Nps concentration increases, the more the inhibition efficiency increases. Moreover, the diameter of the fungal colony almost does not increase and could inhibit $93.98 \%$ of the fungal growth at the $450 \mathrm{ppm} \mathrm{Cu}$ Nps concentration after a 9-day incubation.

\section{Competing Interests}

The authors declare that they have no competing interests.

\section{Acknowledgments}

The authors thank administration boards of University of Science, Vietnam National University Ho Chi Minh City and Ho Chi Minh City University of Technology (HUTECH) for supporting facilities. This research is funded by Ho Chi Minh City University of Technology (HUTECH).

\section{References}

[1] M. Sahu and P. Biswas, "Single-step processing of copper-doped titania nanomaterials in a flame aerosol reactor," Nanoscale Research Letters, vol. 6, no. 1, article 441, pp. 1-14, 2011.

[2] H. Tian, X. L. Zhang, J. Scott, C. Ng, and R. Amal, “ $\mathrm{TiO}_{2}$ supported copper nanoparticles prepared via ion exchange for photocatalytic hydrogen production," Journal of Materials Chemistry A, vol. 2, no. 18, pp. 6432-6438, 2014.

[3] H. M. Yadav, S. V. Otari, V. B. Koli et al., "Preparation and characterization of copper-doped anatase $\mathrm{TiO}_{2}$ nanoparticles with visible light photocatalytic antibacterial activity," Journal of Photochemistry and Photobiology A: Chemistry, vol. 280, pp. 32-38, 2014.

[4] C. S. Chen, C. C. Chen, T. W. Lai, J. H. Wu, C. H. Chen, and J. F. Lee, "Water adsorption and dissociation on Cu nanoparticles," Journal of Physical Chemistry C, vol. 115, no. 26, pp. 12891-12900, 2011.

[5] S. T. H. Sherazi, R. A. Soomro, S. Uddin, and N. Memon, "Synthesis and characterizations of highly efficient copper nanoparticles and their use in ultra fast catalytic degradation of organic dyes," Advanced Materials Research, vol. 829, pp. 93-99, 2013.

[6] H.-J. Hwang, W.-H. Chung, and H.-S. Kim, "In situ monitoring of flash-light sintering of copper nanoparticle ink for printed electronics," Nanotechnology, vol. 23, no. 48, Article ID 485205, 2012.

[7] S. Magdassi, M. Grouchko, and A. Kamyshny, "Copper nanoparticles for printed electronics: routes towards achieving oxidation stability," Materials, vol. 3, no. 9, pp. 4626-4638, 2010.

[8] X.-F. Tang, Z.-G. Yang, and W.-J. Wang, "A simple way of preparing high-concentration and high-purity nano copper colloid for conductive ink in inkjet printing technology," Colloids and Surfaces A: Physicochemical and Engineering Aspects, vol. 360, no. 1-3, pp. 99-104, 2010.

[9] B. K. Park, S. Jeong, D. Kim, J. Moon, S. Lim, and J. S. Kim, “Synthesis and size control of monodisperse copper nanoparticles by polyol method," Journal of Colloid and Interface Science, vol. 311, no. 2, pp. 417-424, 2007.

[10] A. D. Karthik and K. Geetha, "Synthesis of copper precursor, copper and its oxide nanoparticles by green chemical reduction method and its antimicrobial activity," Journal of Applied Pharmaceutical Science, vol. 3, no. 5, pp. 16-21, 2013.

[11] R. Betancourt-Galindo, P. Y. Reyes-Rodriguez, B. A. PuenteUrbina et al., "Synthesis of copper nanoparticles by thermal decomposition and their antimicrobial properties," Journal of Nanomaterials, vol. 2014, Article ID 980545, 5 pages, 2014.

[12] A. K. Chatterjee, R. K. Sarkar, A. P. Chattopadhyay, P. Aich, R. Chakraborty, and T. Basu, "A simple robust method for synthesis of metallic copper nanoparticles of high antibacterial potency against E. coli," Nanotechnology, vol. 23, no. 8, Article ID 085103, 2012.

[13] A. K. Chatterjee, R. Chakraborty, and T. Basu, "Mechanism of antibacterial activity of copper nanoparticles," Nanotechnology, vol. 25, no. 13, Article ID 135101, 2014.

[14] A. M. Muthukrishnan, "Green synthesis of copper-chitosan nanoparticles and study of its antibacterial activity," Journal of Nanomedicine \& Nanotechnology, vol. 6, no. 1, 2015.

[15] M. S. Usman, M. E. El Zowalaty, K. Shameli, N. Zainuddin, M. Salama, and N. A. Ibrahim, "Synthesis, characterization, and antimicrobial properties of copper nanoparticles," International Journal of Nanomedicine, vol. 8, pp. 4467-4479, 2013.

[16] A. Servin, W. Elmer, A. Mukherjee et al., "A review of the use of engineered nanomaterials to suppress plant disease and enhance crop yield," Journal of Nanoparticle Research, vol. 17, no. 2, pp. 1-21, 2015.

[17] C. Booth, "The present status of fusarium taxonomy," Annual Review of Phytopathology, vol. 13, no. 1, pp. 83-93, 1975.

[18] D. S. Egel and R. D. Martyn, "Fusarium wilt of watermelon and other cucurbits," The Plant Health Instructor, 2007.

[19] K. A. Yadeta and B. P. H. J. Thomma, "The xylem as battleground for plant hosts and vascular wilt pathogens," Frontiers in Plant Science, vol. 4, article 97, 2013.

[20] P. E. Nelson, M. C. Dignani, and E. J. Anaissie, “Taxonomy, biology, and clinical aspects of Fusarium species," Clinical Microbiology Reviews, vol. 7, no. 4, pp. 479-504, 1994.

[21] S. Mandal, N. Mallick, and A. Mitra, "Salicylic acid-induced resistance to Fusarium oxysporum f. sp. lycopersici in tomato," Plant Physiology and Biochemistry, vol. 47, no. 7, pp. 642-649, 2009.

[22] K. Lairini and M. Ruiz-Rubio, "Detection of tomatinase from Fusarium oxysporum f. sp. Lycopersici in infected tomato plants," Phytochemistry, vol. 45, no. 7, pp. 1371-1376, 1997.

[23] K. Czaczyk, K. Trojanowska, and A. Mueller, "Antifungal activity of Bacillus coagulans against Fusarium sp," Acta Microbiologica Polonica, vol. 51, no. 3, pp. 275-283, 2002.

[24] N. Durán, P. D. Marcato, R. De Conti, O. L. Alves, F. T. M. Costa, and M. Brocchi, "Potential use of silver nanoparticles on pathogenic bacteria, their toxicity and possible mechanisms of action," Journal of the Brazilian Chemical Society, vol. 21, no. 6, pp. 949-959, 2010.

[25] B. M. Prabhu, S. F. Ali, R. C. Murdock, S. M. Hussain, and M. Srivatsan, "Copper nanoparticles exert size and concentration dependent toxicity on somatosensory neurons of rat," Nanotoxicology, vol. 4, no. 2, pp. 150-160, 2010.

[26] A. P. Ingle, N. Duran, and M. Rai, "Bioactivity, mechanism of action, and cytotoxicity of copper-based nanoparticles: a review," Applied Microbiology and Biotechnology, vol. 98, no. 3, pp. 1001-1009, 2014. 
[27] P. Kanhed, S. Birla, S. Gaikwad et al., "In vitro antifungal efficacy of copper nanoparticles against selected crop pathogenic fungi," Materials Letters, vol. 115, pp. 13-17, 2014.

[28] H. Chen, J.-H. Lee, Y.-H. Kim et al., "Metallic copper nanostructures synthesized by a facile hydrothermal method," Journal of Nanoscience and Nanotechnology, vol. 10, no. 1, pp. 629-636, 2010.

[29] B. Wang, S. Chen, J. Nie, and X. Zhu, "Facile method for preparation of superfine copper nanoparticles with high concentration of copper chloride through photoreduction," RSC Advances, vol. 4, no. 52, pp. 27381-27388, 2014.

[30] X. Zhu, B. Wang, F. Shi, and J. Nie, "Direct, rapid, facile photochemical method for preparing copper nanoparticles and copper patterns," Langmuir, vol. 28, no. 40, pp. 14461-14469, 2012.

[31] N. Nishida, A. Miyashita, N. Hashimoto, H. Murayama, and H. Tanaka, "Regenerative synthesis of copper nanoparticles by photoirradiation," The European Physical Journal D, vol. 63, no. 2, pp. 307-310, 2011.

[32] M. Blosi, S. Albonetti, M. Dondi, C. Martelli, and G. Baldi, "Microwave-assisted polyol synthesis of $\mathrm{Cu}$ nanoparticles," Journal of Nanoparticle Research, vol. 13, no. 1, pp. 127-138, 2011.

[33] M. I. Dar, S. Sampath, and S. A. Shivashankar, "Microwaveassisted, surfactant-free synthesis of air-stable copper nanostructures and their SERS study," Journal of Materials Chemistry, vol. 22, no. 42, pp. 22418-22423, 2012.

[34] A. Umer, S. Naveed, N. Ramzan, and M. S. Rafique, "Selection of a suitable method for the synthesis of copper nanoparticles," Nano, vol. 7, no. 5, Article ID 1230005, 2012.

[35] J. Xiong, Y. Wang, Q. Xue, and X. Wu, "Synthesis of highly stable dispersions of nanosized copper particles using l-ascorbic acid," Green Chemistry, vol. 13, no. 4, pp. 900-904, 2011.

[36] B. Zümreoglu-Karan, "A rationale on the role of intermediate $\mathrm{Au}(\mathrm{III})$-vitamin $\mathrm{C}$ complexation in the production of gold nanoparticles," Journal of Nanoparticle Research, vol. 11, no. 5, pp. 1099-1105, 2009.

[37] A. Khan, A. Rashid, R. Younas, and R. Chong, "A chemical reduction approach to the synthesis of copper nanoparticles," International Nano Letters, vol. 6, no. 1, pp. 21-26, 2016.

[38] H. Kang, B.-G. Kim, H. B. Na, and S. Hwang, "Anti-galvanic reduction of silver ion on gold and its role in anisotropic growth of gold nanomaterials," The Journal of Physical Chemistry C, vol. 119, no. 46, pp. 25974-25982, 2015.

[39] Y. C. Zhang, R. Xing, and X. Ya. Hu, "A green hydrothermal route to copper nanocrystallites," Journal of Crystal Growth, vol. 273, no. 1-2, pp. 280-284, 2004.

[40] Q.-L. Zhang, Z.-M. Yang, B.-J. Ding, X.-Z. Lan, and Y.-J. Guo, "Preparation of copper nanoparticles by chemical reduction method using potassium borohydride," Transactions of Nonferrous Metals Society of China, vol. 20, no. 1, pp. s240-s244, 2010.

[41] J. M. Vincent, "Distortion of fungal hyphæ in the presence of certain inhibitors," Nature, vol. 159, no. 4051, p. 850, 1947.

[42] C. Barrière, K. Piettre, V. Latour et al., "Ligand effects on the air stability of copper nanoparticles obtained from organometallic synthesis," Journal of Materials Chemistry, vol. 22, no. 5, pp. 2279-2285, 2012.

[43] J. A. Creighton and D. G. Eadon, "Ultraviolet-visible absorption spectra of the colloidal metallic elements," Journal of the Chemical Society, Faraday Transactions, vol. 87, no. 24, pp. 38813891, 1991.
[44] N. A. Dhas, C. P. Raj, and A. Gedanken, "Synthesis, characterization, and properties of metallic copper nanoparticles," Chemistry of Materials, vol. 10, no. 5, pp. 1446-1452, 1998.

[45] P. K. Khanna, T. S. Kale, M. Shaikh, N. K. Rao, and C. V. V. Satyanarayana, "Synthesis of oleic acid capped copper nano-particles via reduction of copper salt by SFS," Materials Chemistry and Physics, vol. 110, no. 1, pp. 21-25, 2008.

[46] H. Zhu, C. Zhang, and Y. Yin, "Novel synthesis of copper nanoparticles: influence of the synthesis conditions on the particle size," Nanotechnology, vol. 16, no. 12, pp. 3079-3083, 2005.

[47] P. Martis, A. Fonseca, Z. Mekhalif, and J. Delhalle, "Optimization of cuprous oxide nanocrystals deposition on multiwalled carbon nanotubes," Journal of Nanoparticle Research, vol. 12, no. 2, pp. 439-448, 2010.

[48] M. S. M. Suan, M. R. Johan, N. L. Hawari, and H. A. Ching, "Annealing effects on the properties of copper oxide thin films prepared by chemical deposition," International Journal of Electrochemical Science, vol. 6, no. 12, pp. 6094-6104, 2011.

[49] R. B. Viana, A. B. F. da Silva, and A. S. Pimentel, "Infrared spectroscopy of anionic, cationic, and zwitterionic surfactants," Advances in Physical Chemistry, vol. 2012, Article ID 903272, 14 pages, 2012.

[50] M. A. Ben Aissa, B. Tremblay, A. Andrieux-Ledier, E. Maisonhaute, N. Raouafi, and A. Courty, "Copper nanoparticles of well-controlled size and shape: a new advance in synthesis and self-organization," Nanoscale, vol. 7, no. 7, pp. 3189-3195, 2015. 

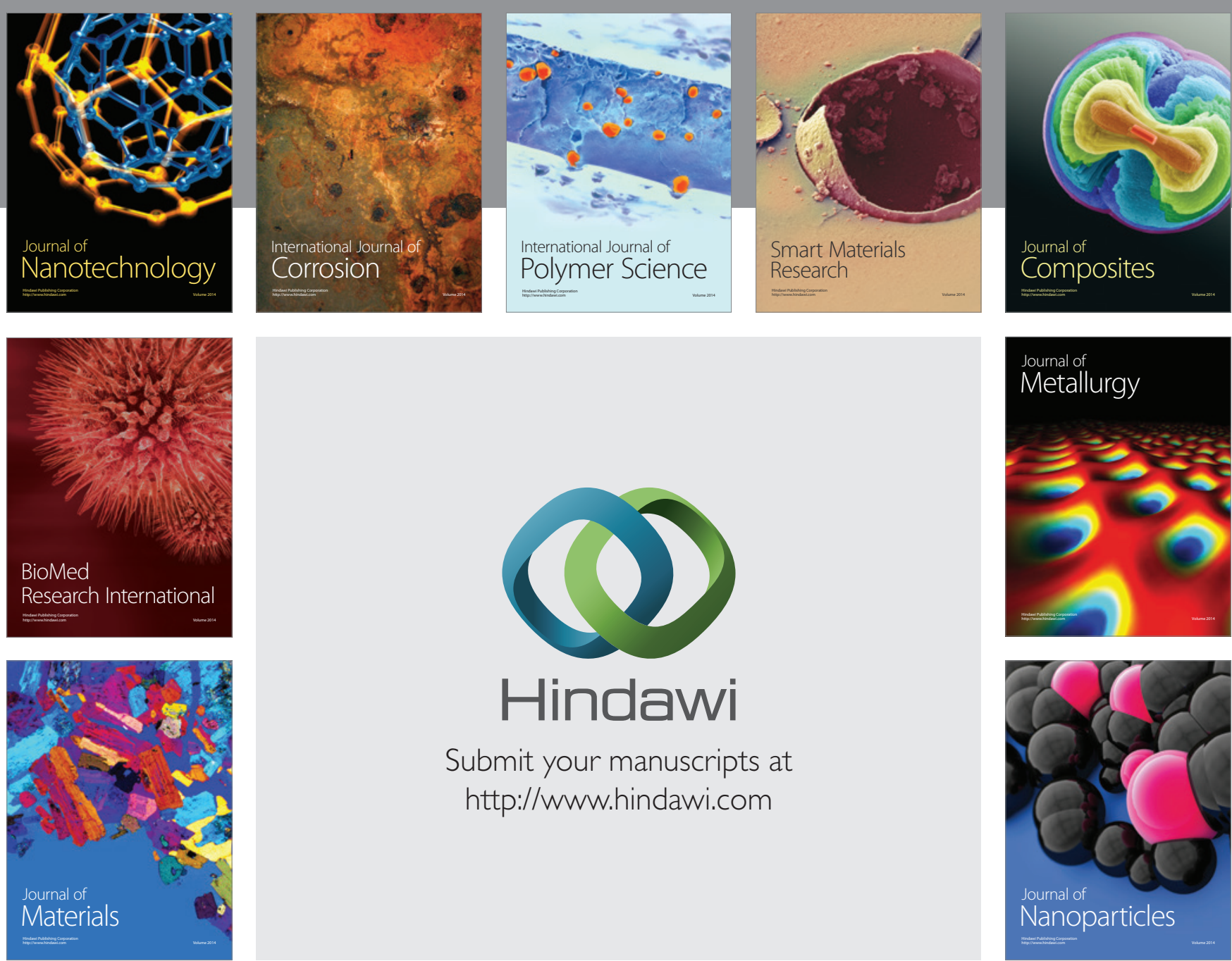

\section{Hindawi}

Submit your manuscripts at

http://www.hindawi.com

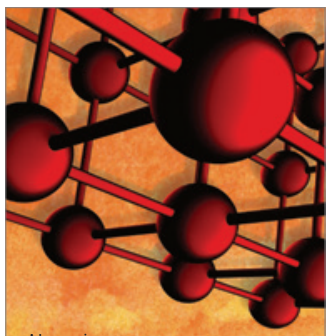

Materials Science and Engineering
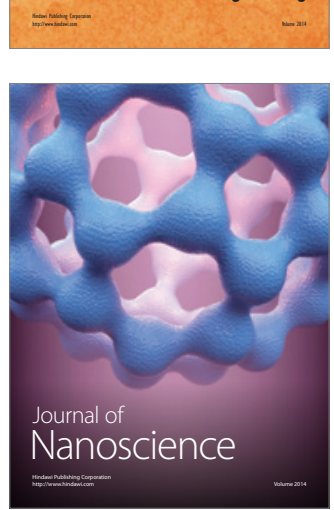
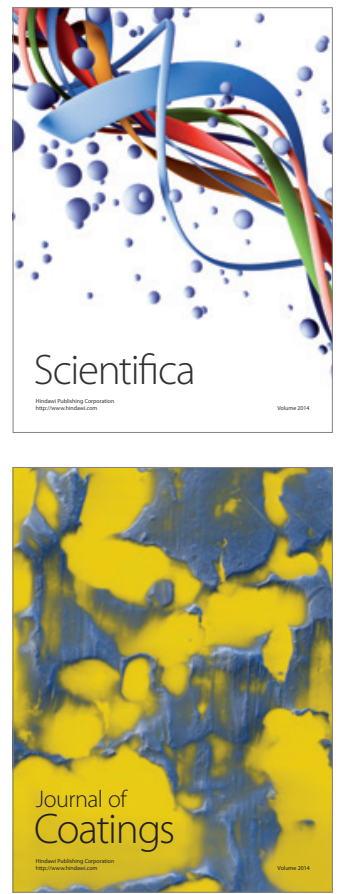
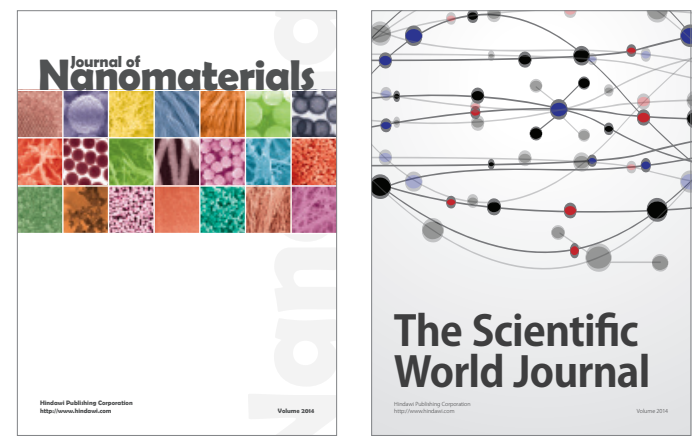

The Scientific World Journal
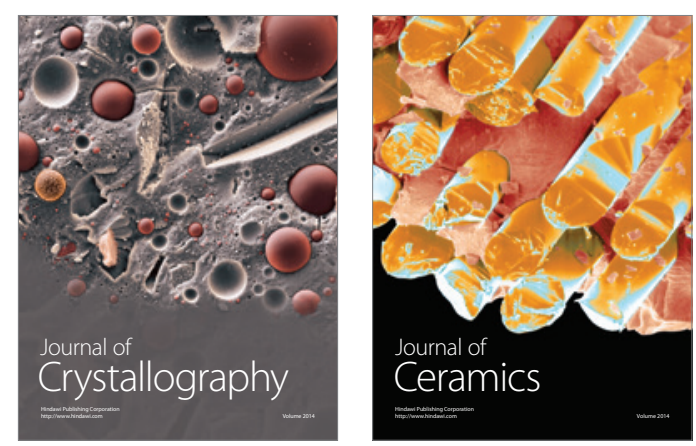
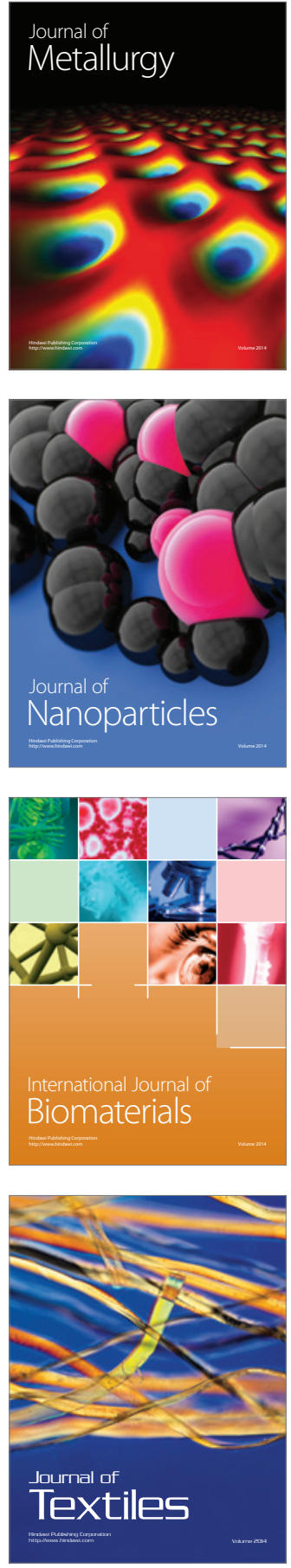